\title{
Tourette's syndrome and creativity
}

\section{Exploiting the ticcy witticisms and witty ticcicisms}

Benjamin Simkin's article on Mozart and Gilles de la Tourette syndrome in this issue provides at least circumstantial evidence that Mozart may have had the hyperactivity, tics, sudden impulses and odd motor behaviours, echolalia, palilalia, love of nonsense words, and driven inner rhythms that so often accompany Tourette's syndrome (p 1563). ${ }^{1}$ Further evidence has been provided by Gunne. ${ }^{2}$

The case for Mozart's having Tourette's syndrome does not strike me as entirely convincing. But the case for Samuel Johnson having the syndrome, though also circumstantial, is extremely strong and, to my mind, entirely convincing. Johnson was observed to have innumerable strange rituals and compulsions, tics, gesticulations, and a great range of involuntary ejaculations and mimicries. One cannot avoid thinking that his enormous spontaneity, antics, and lightning quick wit had an organic connection with his accelerated motor impulsive state.

If this was just a question of pathologising it would be of limited interest. The real question is whether Mozart and Johnson were singular characters, and creators, despite having Tourette's syndrome, or whether their Tourette's played a significant part in, lent a particular flavour to, their character and creativity. And what, in general, is the relation of Tourette's to personality and creativity?

The matter is complicated because there are different forms of the syndrome. At one extreme is the stereotypic form with its simple motor tics, iterations, perseverations, and brief, explosive vocalisations. At the other extreme is an elaborate, innovatory, phantasmagoric form which is especially remarkable for its mimicry, antics, playfulness, extravagance, impudence, audacity, inventions, dramatisations, unexpected and sometimes surreal associations, intense and uninhibited affects, speed, "go," vivid imagery and memory, hunger for stimuli and incontinent reactivity, and constant reaching into inner and outer worlds for new material to Tourettise, to permute and transform.

Stereotypic Tourette's syndrome is usually regarded as a distress, perhaps a disability, an irrelevance, and annoyance, or, in the words of one patient, "completely useless." If one is creative one may be so despite such Tourette's, as with a Tourettic surgeon I have recently described. ${ }^{+}$(I now know eight surgeons with Tourette's, as well as an internist, two neurologists, an obstetrician, and a psychiatrist.)

But phantasmagoric Tourette's syndrome is another matter entirely, and while it can also cause much distress and disability it can hardly fail to touch, to interact with, a person's character and creativity and even to lend that person some of its own striking "character." This was clear with my patient "Witty Ticcy Ray," who believed that there was a close analogy between his wit and his tics and spoke of his "ticcy witticisms" and his "witty ticcicisms," feeling both as expressions of the sudden, unexpected swerves and twists, the irruptions and interruptions, in his mental and motor stream. ${ }^{5}$ Similarly, when playing ping pong he would make "sudden, nervous, frivolous shots"-shots which, without being illegal, were so fast, so unpredictable, as to be unanswerable. (Similar, stunning "motor genius" may be seen in some patients after encephalitis. $\left.{ }^{6}\right)$ And with music, too: he was a weekend drummer of real virtuosity, well known for his sudden and wild improvisations. These too, while arising from a tic or a compulsive hitting of a drum, would be elaborated into entire Tourettic performances. ${ }^{5}$

In a recent autobiographical sketch by another jazz musician, David Aldridge writes of this inseparability of Tourette's and creativity: "Rhythm and Tourette Syndrome have been intertwined from the first day I found that drumming on a table could mask my jerky hand, leg and neck movements . . could harness my unbounding [Tourettic] energy, directing it into an orderly flow." Aldridge goes on to describe how, with jazz, the "rollercoaster ride" of Tourette's syndrome could be transformed because he was riding it, commanding it, not it him. A similar conjunction of the syndrome and creativity is responsible for the "tic dancing" so popular at the Tourette Syndrome Association's socials.

Artists and writers may use their Tourette's. For one gifted Tourettic artist of my acquaintance the half convulsive excitement of Tourette's continually stimulates his perceptions and imagination, producing a ceaseless stream of extraordinary images. Some of these are trivial, some absurd, but many have a deep creative force and lend his art a range, intensity, exuberance, and surreal or dreamlike quality which one feels, he feels, it might not otherwise have. And I know of one Tourettic writer with two strikingly different modes of writing. In one he is at pains to resist his Tourette's and writes short, sober, rather formal essays and reviews; in the other he lets himself go and, at great speed, writes huge, meandering, fantastical (and often coprolalic) novels, in which he gives his Tourettic fancies full rein.

Pavlov speaks of "the blind force of the subcortex": Tourette's syndrome is such a force-blind, impersonal - but one that erupts within the particularity of the individual. Luria, similarly, when speaking of the effects of a physio- 
logical hypertrophy of memory on an individual speaks of this as an "it" and the individual as an "I." complex relation between such an "it" and an "I," and the "it" of Tourette's is far more complex, for it can draw, like a dream, on the entire range of instinctual and preconscious forces, which the conscious mind can then manipulate.

Perhaps it is in some complex act of balance or negotiation-partly deferring to, partly mastering, the energy of Tourette's - that the most potent Tourettic creativities arise. ${ }^{9}$ One also sees this in Tourettic athletes: Jim Eisenreich, a baseball player, and Chris Jackson, a basketball player, who do not so much suppress as use their Tourette's, its speed, its spontaneity, to their own advantage. And there is a Tourettic disc jockey in Iowa, whose language, off the air, is a tissue of profanities but who, once the "on air" sign appears, has no profanities, no excursions, only force and speed, the rollercoaster of Tourette's orchestrated and mastered. I know actors with Tourette's syndrome, who may be similarly distracted or fragmented by their Tourette's offstage but are, seemingly, Tourette free on stage - but "Tourette free" is not the right phrase, for what one sees is Tourette's organised and mastered, its force all coordinated in the act of performance. Some Tourettic actors speak here of the integrating power of a role or identity.
One must not romanticise Tourette's, or any other disease, nor make a romantic equation of disease and creativity (as Thomas Mann so often seemed to do). Creativity is usually in a different realm from disease. But with a disorder like Tourette's syndrome, especially in its phantasmagoric form, one may have the rather rare situation of a biological condition becoming creative or becoming an integral part of the identity and creativity of an individual. Whether this was the case with Mozart is unclear, but that it occurs among others, and often, is quite beyond question.

Professor of Clinical Neurology,

Albert Einstein College of Medicine,

299 West 12th Street, 14C

New York, NY 10014

USA

1 Simkin B. Mozart's scatological disorder. BMF 1992;305:1563-7.

2 Gunne LM. Hade Mozart Tourettes Syndrome. Läkartidningen 1991;88:4325-6.

3 Murray TJ. Dr Samuel Johnson's movement disorder. BMF 1979;i:1610-4.

4 Sacks O. A surgeon's life. New Yorker 1992; March 16: 85-94.

5 Sacks O. The man who mistook his wife for a hat. London: Picador, 1986

6 Sacks O. Awakenings. London: Picador, 1990.

7 Aldridge DR. Rhythm man. In: Seligman AW, Hilkevich JS, eds. Don't think about monkeys. Duarte, CA: Hope Press, 1992:173-82.

8 Luria AR. The mind of a mnemonist. Cambridge, MA, and London: Harvard University Press, 1968.

9 Sacks OW. Neuropsychiatry and Tourette's. In: Mueller J, ed. Neurology and psychiatry: a meeting

of minds. Basel: Karger, 1989:156-74.

\section{Hospital twinning in Europe}

\section{Britain could offer more to central and east European countries}

Amid the concerns about the European Community's problems and priorities it is worth emphasising that Europe extends a long way beyond the 12 member states. People in central and eastern Europe, struggling to restructure their health services amid economic and political uncertainty, are looking to their counterparts in the West for information and support. How best can they respond?

On one level there is tremendous interest in the West's health care reforms. All countries are trying to contain the costs of health care, but which model is best? At another level some hospitals and institutions need basic humanitarian help. Midway, and most importantly, those concerned with providing medical care seek communication with their peers in the West. They want more information and an exchange of values, knowledge, and skills.

One way of doing this is through "twinning" Western hospitals with comparable hospitals in the East, an activity that gained considerable momentum after the political changes of 1989-90. Most of the links have been established between countries with historical, geographical, and cultural ties. For example, Belgium and France have many links with hospitals in Romania; Holland and Germany with Czechoslovakia and Hungary; and Denmark with Poland and Lithuania. Most have been triggered by personal contacts between doctors, nurses, administrators, and managers.

The total number of links is unknown, although some countries, notably Denmark and Switzerland, have quantified them. Switzerland has 60 projects in Romania alone, and Nils Ulritz, of Veska (the Swiss Hospital Association), estimates that about a fifth of eligible Swiss hospitals have set up links with countries from Albania to Estonia.

Given its usually serendipitous beginning and the varying receptivity of different countries to the idea, twinning has, unsurprisingly, developed haphazardly. To avoid duplication of effort the Hospital Committee of the European Community (a self financing independent association) has suggested establishing a central database. New projects could then be set up more systematically, and a list could be kept of hospitals $\overline{0}$ seeking partnerships. At a recent meeting of the committee $\frac{\mathscr{D}}{\circ}$ with representatives from the World Health Organisation $\stackrel{2}{2}$ Europe this proposal failed to get translated into action: $\overrightarrow{\vec{c}}$ agreement could not be reached on what information to store, who should have access to it, or how the project might be funded.

Broad agreement exists, however, on the criteria for successful twinning (or tripling or quadrupling-networks? can be developed and the activity not confined to hospital $\frac{1}{3}$. based medical groups). Goodwill and generosity must be accompanied by meticulous planning and organisation. Clear, realistic objectives must be agreed by all partners-whether 0 they relate to exchange of staff, training programmes, access $N$ to medical publications, or the transfer and maintenance of equipment. A timetable and legal framework must be drawn up and resources found. Many northern European countries $\vec{N}$ (but not Britain) have specific funds available for establishing links with east European hospitals, as do the World Bank, the European Bank for Reconstruction and Development in Eastern Europe, and the European Commission's PHARE ${ }_{\bar{\Phi}}$ programme (based in Directorate General I). The Hospital $\stackrel{\oplus}{+}$ Committee of the European Community produces a newsletter $T$ on twinning, and the French Society for Cooperation and $\stackrel{0}{+}$ Development of Health Facilities and Structures (ACODESS) produces a "how to do it" manual.

Plans should take into account the need for sustained effort on both sides so that links do not founder after the initialo enthusiasm wanes. Much depends on maintaining and fostering good relationships between people and recognising that simple measures such as providing accommodation for ${ }^{2}$ visitors from the East can help keep costs low. Evidence that twinning has positive long term effects is sparse and it is 